\title{
Rearrangement of the Genes for the Beta and Gamma Chains of the T Cell Receptor Is Rarely Observed in Adult B Cell Lymphoma and Chronic Lymphocytic Leukemia
}

\author{
Alan C. Aisenberg, Barbara M. Wilkes, and Joseph O. Jacobson \\ Hematology/Oncology Unit of the Department of Medicine, Massachusetts General Hospital, Boston, Massachusetts 02114
}

\begin{abstract}
We determined the configuration of the genes for the beta $\left(T_{\text {beta }}\right)$ and gamma $\left(T_{\text {gamman }}\right)$ chains of the $T$ cell receptor in DNA from 100 consecutive cases of $B$ cell lymphoma and $B$ cell chronic lymphocytic leukemia (B-CLL), and compared the findings with those in $18 \mathrm{~T}$ cell neoplasms. In 7 of the $100 \mathrm{~B}$ cell specimens, a single nongermline band was detected after digestion with the restriction enzyme BamHI, but the rearrangement could be confirmed with a second restriction enzyme in only two. The B cell fragments were small in size and of limited size diversity when compared with the $T$ cell cases, and germline bands of equal intensity were present. $A$ rearrangement of the $T_{\text {gamman }}$ gene was never seen in a $B$ cell sample. In contrast, $\mathbf{T}$ cell specimens usually rearranged both alleles of $T_{\text {beta }}(15$ of 18$)$, the rearrangement could be confirmed with a second restriction enzyme (17 of 18 ), both alleles of the first constant region gene segment of $T_{\text {beta }}$ always underwent either rearrangement or deletion, and the $T_{\text {ganma }}$ gene was also rearranged or deleted (17 of 18$)$. We conclude that ordered rearrangement of the $T$ cell receptor is a rare event in $B$ cell lymphoma and B-CLL. T cell receptor gene studies allow B and T cell lymphomas to be distinguished from each other and from common acute lymphoblastic leukemia antigen-positive non-T, non-B acute lymphoblastic leukemia.
\end{abstract}

\section{Introduction}

When clonally rearranged $T$ cell receptor genes were first detected in T cell malignancies (1-3), it was hoped that the finding would prove a hallmark of neoplasms of this cell lineage. However, within a year of that discovery, several laboratories reported rearranged $T$ cell receptor gamma chain $\left(T_{\text {gamma }}\right)$, and less frequently, $T$ cell receptor beta chain $\left(T_{\text {beta }}\right)$ genes in non-T cell, non-B cell, acute lymphoblastic leukemia (non$\mathrm{T}$ - , non-T-ALL) ${ }^{1}$ (3-5), a disorder of pre-B cell lineage (6). It

Reprint requests should be addressed to Dr. Aisenberg, Massachusetts General Hospital, Boston, MA 02114.

Received for publication 23 February 1987 and in revised form 6 May 1987.

1. Abbreviations used in this paper: ALL, acute lymphoblastic leukemia; B- and T-ALL, B and T cell ALL; ATL, adult T cell leukemia; CLL, chronic lymphocytic leukemia; B- and T-CLL, B and T cell CLL;

J. Clin. Invest.

(C) The American Society for Clinical Investigation, Inc.

0021-9738/87/10/1209/06 \$2.00

Volume 80, October 1987, 1209-1214 became important to establish if such rearranged $T$ cell receptor genes were restricted to this pre-B cell lineage (ALL), or whether they could be demonstrated in mature B cell populations as well. We have therefore examined the status of the $T$ cell receptor genes in 100 consecutive specimens of B cell lymphoma and chronic leukemia, and report here our failure to find a single adult $\mathrm{B}$ cell neoplasm with convincing rearrangement of both $T_{\text {beta }}$ and $T_{\text {gamma }}$ genes.

\section{Methods}

Patients and surface marker analysis. An earlier publication (7) analyzed surface markers and Ig genes in 100 consecutive adult patients with non-Hodgkin's lymphoma or B cell chronic lymphocytic leukemia (B-CLL). Biopsy specimens were subclassified according to a modified Rappaport system for non-Hodgkin's lymphoma (8), and the diagnosis of B-CLL was based on conventional morphologic criteria. The 100 cases were comprised of 32 of B-CLL, 23 of follicular lymphoma (lymphocytic or mixed), 23 of diffuse large cell lymphoma, 14 of diffuse poorly differentiated lymphocytic lymphoma, and 8 miscellaneous lymphomas. Lymphoblastic lymphoma and leukemias of $\mathrm{T}$ cell lineage were specifically excluded from this consecutive series. In all cases, lymphocyte surface markers were determined on suspensions prepared from fresh biopsy material (lymphoma) or Ficoll-Hypaque gradient-purified blood cells (leukemia).

Surface immunoglobulin (SIg) was assessed with a fluorescence microscope and fluorescein-conjugated heteroantisera specific for human IgM and IgG heavy chains, and the kappa and lambda light chains (Meloy Laboratories Inc., Springfield, VA). The suspensions were also evaluated with the following monoclonal antibodies: OKT4 (inducer-helper T cells); OKT8 (cytotoxic-suppressor T cells); OKT11 (sheep cell receptor); and B1 (B cells). Except B1, which was a product of Coulter Diagnostics (Hialeah, FL), the monoclonal antibodies were obtained from the Ortho Pharmaceutical (Raritan, NJ). The SIg was of kappa light chain type in 57 cases and lambda light chain type in 26: in the remainder a predominant light chain could not be determined. Details of the surface marker techniques employed are available in the earlier publication (7).

A second series of cases, comprised of 18 consecutive patients with various $T$ cell malignancies, was studied in similar fashion. The $T_{\text {beta }}$ gene findings in three of these patients, case 1 in the cutaneous $T$ cell lymphoma (CTCL), adult T cell leukemia (ATL), and T CLL categories, were described in an earlier report (2).

Southern blot analysis of genomic DNA. High molecular weight DNA was prepared from each of the immunotyped specimens, and 6-10 $\mu \mathrm{g}$ was digested with appropriate restriction enzymes (New England Biolabs, Beverly, MA) and subjected to electrophoresis on $0.8 \%$

CTCL, cutaneous $T$ cell lymphoma; $J_{H}$, heavy chain joining region; SIg, surface immunoglobulin; $T_{\text {beta }}, T$ cell receptor beta chain; $T_{\text {gamma }}$, $T$ cell receptor gamma chain. 
Table I. Cell Surface Markers and Immunoglobulin Gene Configuration in B Cell Neoplasms

\begin{tabular}{|c|c|c|c|c|c|c|c|c|c|c|c|}
\hline \multirow[b]{2}{*}{ Case no. diagnosis } & \multicolumn{9}{|c|}{ Surface markers* } & \multicolumn{2}{|c|}{ Ig genes } \\
\hline & G & $\mathbf{M}$ & $\kappa$ & $\lambda$ & B1 & T4 & T8 & $\mathbf{E}$ & T11 & $\mathbf{J}_{\mathbf{H}}$ & $\mathbf{C}_{\boldsymbol{x}}$ \\
\hline 1. B-CLL & 5 & 67 & 3 & 5 & 52 & 4 & 5 & 7 & 5 & $\mathbf{R R}$ & G \\
\hline 2. B-CLL & 3 & 2 & 2 & 7 & 85 & 2 & 4 & 7 & 6 & $\mathbf{R} \mathbf{R}$ & G \\
\hline 3. WDLL & 39 & 25 & 82 & 0 & 85 & 10 & 4 & 7 & - & $\mathbf{R R}$ & $\mathbf{G}$ \\
\hline 4. $\mathrm{L} / \mathrm{H}(\mathrm{N})$ & 78 & 0 & 4 & 2 & 83 & - & - & 19 & 一 & $\mathbf{R R}$ & $\mathbf{R}$ \\
\hline 5. $\mathrm{L} / \mathrm{H}(\mathrm{D})$ & 14 & 7 & 8 & 5 & 37 & 13 & 3 & 14 & 17 & $\mathbf{R R}$ & $\mathbf{R}$ \\
\hline 6. $\mathrm{L} / \mathrm{H}(\mathrm{D} / \mathrm{N})$ & 72 & 0 & 69 & 2 & 70 & 17 & 6 & 35 & 16 & $\mathbf{R R}$ & $\mathbf{R}$ \\
\hline 7. DHL & 18 & 0 & 17 & 0 & - & - & - & 5 & - & $\mathbf{R}$ & $\mathbf{R}$ \\
\hline
\end{tabular}

WDLL, diffuse small cell (well differentiated) lymphocytic lymphoma; L, lymphocytic; H, histiocytic; N, nodular; D, diffuse; DHL, diffuse large cell (histiocytic) lymphoma; R, rearrangement; G, germline; E, E rosettes. * Surface markers are expressed as percent of cells staining. The following monoclonal antibodies were employed: B1 (B cells); T4 (helper T cells); T8 (cytotoxic suppressor T cells); and T1 1 (sheep cell receptor).

agarose gel slabs. In the earlier report (7), the restriction enzymes EcoRI and SacI were employed with a probe specific for the Ig-heavy chain joining region $\left(\mathrm{J}_{\mathrm{H}}\right)$ to study heavy chain gene rearrangement, whereas the enzyme BamHI was used with a probe specific for the kappa light chain constant region to study kappa gene rearrangement. $97 \%$ of the consecutive series displayed $\mathrm{J}_{\mathrm{H}}$ rearrangement, including 12 of 15 that were SIg negative (7).

In the present work the restriction enzymes BamHI, EcoRI, and HindIII were used to investigate the $T_{\text {beta }}$ and $T_{\text {gamma }}$ genes. After denaturation and neutralization, the DNA was transferred to nitrocellulose paper by the technique of Southern (9). Hybridization was carried out at $68^{\circ} \mathrm{C}$ in a solution of $5 \times \mathrm{SET}(1 \times \mathrm{SET}$ : $15 \mathrm{mM} \mathrm{NaCl}$; $\mathrm{mM}$ EDTA; $30 \mathrm{mM}$ Tris $\mathrm{HCl}$, pH 8.0); $1 \times$ Denhardt's solution; $0.5 \%$ sodium dodecyl sulfate (SDS); $10 \%$ dextran sulfate; $20 \mathrm{mM} \mathrm{Na}_{2} \mathrm{HPO}_{4}$, pH 7.0; $40 \mu \mathrm{g} / \mathrm{ml}$ salmon sperm DNA; and $0.025-0.10 \mu \mathrm{g}$ of nicktranslated ${ }^{32} \mathrm{P}$-labeled $\left(10^{7} \mathrm{dpm}\right)$ DNA probe. Human complementary DNA probes specific for the constant region of $\mathrm{T}_{\text {beta }}$ (a BglII/EcoRV fragment of YT35 [10]) and for the joining region of $T_{\text {gamma }}$ [11]) were employed. Filters were prehybridized for $2 \mathrm{~h}$ at $68^{\circ} \mathrm{C}$ in prehybridization buffer, and hybridized for $15-20 \mathrm{~h}$ at the same temperature. After hybridization, filters were washed successively for 1 -h periods at $68^{\circ} \mathrm{C}$ with $2 \times$ SET containing $0.5 \%$ SDS, $1 \times$ SET with $0.25 \%$ SDS, and twice with $0.5 \times$ SET containing $0.125 \%$ SDS. Autoradiography of the washed filters was carried out for $1-7 \mathrm{~d}$ at $-70^{\circ} \mathrm{C}$ with two intensifying screens. Details of the standard methods are available (12).

\section{Results}

DNA from the 100 patients with B cell lymphoma or B-CLL was first digested with the restriction enzyme BamHI and probed for rearrangement of the gene for the beta chain of the $T$ cell receptor. A novel nongermline band was detected in seven specimens, two in patients with B-CLL, and one in patients with each of the following lymphoma subtypes: small cell (well differentiated) lymphocytic, mixed small and large cell nodular, mixed diffuse, mixed nodular and diffuse, and diffuse large cell (histiocytic) lymphoma. (Rearrangements of the $T_{\text {gamma }}$ gene were not observed in the $100 \mathrm{~B}$ cell specimens.) Table I lists the surface marker and Ig gene findings that establish the B cell lineage of these specimens. Thus, three of the seven displayed a predominant light chain; two more, a predominant heavy chain only; the six studied were B1 positive; and all seven exhibited one or more rearrangements of the $J_{H}$ and in four, kappa light chain constant region genes as well.

The results of $T$ cell receptor genes studies in the seven B cell patients are summarized in Table II and depicted in Fig. 1. The novel $T_{\text {beta }}$ bands observed after BamHI digestion (Fig. 1, left) were of limited size range and size diversity: three were 14.0 kilobase $(\mathrm{kb})$; two, $13.5 \mathrm{~kb}$; one, $11.0 \mathrm{~kb}$, and one, 10.0 $\mathrm{kb}$. The density of the new bands was, with one exception, equal to or less than that of the residual germline band. Efforts to confirm the rearrangements by digestion with other restriction enzymes (EcoRI and HindIII) were successful only in patients 4 and 6 (Fig. 1, center and right). Also, DNA from the seven patients was investigated for rearrangement of the $\mathrm{T}_{\text {gamma }}$ gene after digestion with all three restriction enzymes: in no case was a rearranged band detected (BamHI results are

Table II. Configuration of the Genes for the Beta and Gamma Chains of the T Cell Receptor in B Cell Neoplasms

\begin{tabular}{|c|c|c|c|c|c|c|c|c|}
\hline \multirow[b]{2}{*}{ Case no. } & \multicolumn{4}{|c|}{ Beta chain genes } & \multicolumn{4}{|c|}{ Gamma chain genes } \\
\hline & Bam & Eco (C1) & Hind (C2) & Interpretation & Bam & Eco & Hind & Interpretation \\
\hline 1. & $R(14.0) G$ & $\mathbf{G}$ & $\mathbf{G}$ & $\mathbf{P}$ & G & G & G & G \\
\hline 2. & $\mathrm{R}(10.0) \mathrm{G}$ & - & G & $\mathbf{P}$ & G & G & GP & GP \\
\hline 3. & $\mathbf{R}(13.5) \mathrm{G}$ & G & G & $\mathbf{P}$ & G & $\mathbf{G}$ & G & G \\
\hline 4. & $R(14.0) G$ & G & RG & ?P,?R & G & G & G & G \\
\hline 5. & $\mathbf{R}(13.5) \mathrm{G}$ & $\mathbf{G}$ & G & $\mathbf{P}$ & $\mathbf{G}$ & $\mathbf{G}$ & G & G \\
\hline 6. & $\mathrm{R}(11.0) \mathrm{G}$ & G & RG & ?R,?P & G & G & GP & GP \\
\hline 7. & $R(14.0) G$ & G & G & $\mathbf{P}$ & G & $\mathbf{G}$ & - & G \\
\hline
\end{tabular}

$R$, novel band with size in parentheses; $G$, germline; $P$, polymorphism; ?, possible. 


\section{$\begin{array}{lll}\text { BamHI EcoRI } & \text { Hind III }\end{array}$}

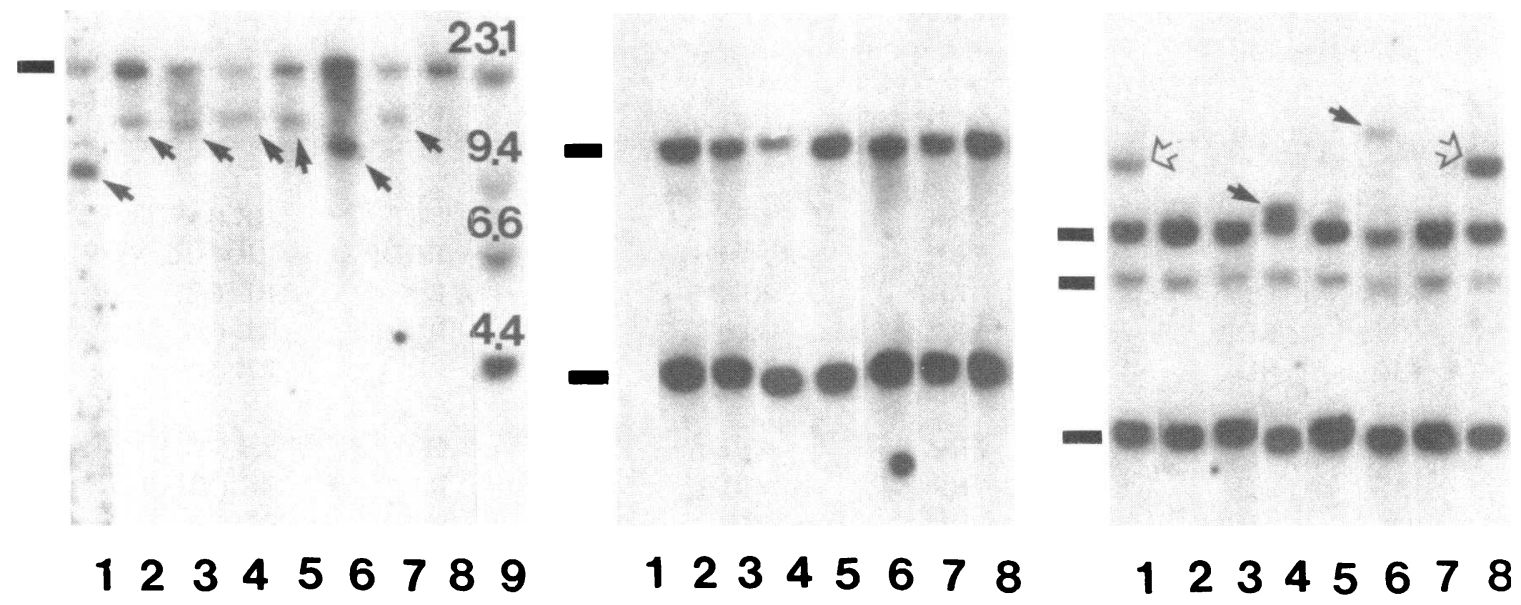

Figure 1. Novel T cell receptor beta chain bands in B cell lymphoma. After digestion with BamHI (left), EcoRI (center) and HindIII (right), the genomic DNA was hybridized with a probe specific for the constant region of the beta chain. The germline positions of the beta chain gene are indicated by the solid bars on the left, and the novel bands by arrows. Cases 1-7 from Tables I and II occupy

depicted in Fig. 2, lanes 1-7), though a previously described polymorphism (13) represented by a 5.0-kb HindIII fragment was observed in two instances.

In Table III, the configuration of the $T_{\text {beta }}$ and $T_{\text {gamma }}$ genes in 18 patients with a variety of unequivocal $T$ cell malignancies is presented to compare with the B cell lymphoma findings. There are striking differences. In 15 of the $18 \mathrm{~T}$ cell neoplasms, both alleles of $T_{\text {beta }}$ were rearranged, and in the remaining 3 , one allele was rearranged and the other deleted (representative rearrangements of $T_{\text {beta }}$ detected by BamHI digestion are depicted in Fig. 3, lanes 7-15). Germline alleles of the first constant region gene of $\mathrm{T}_{\text {beta }}$ were never identified, i.e., the 11-kb germline fragment after EcoRI digestion was always lanes 1-7, respectively; germline DNA derived from a patient with chronic myelogenous leukemia is in lane 8 ; and lane 9 contains a molecular weight marker expressed in kilobase. The open arrows point to a product of partial digestion occasionally seen after digestion with HindIII.

absent: in 10 specimens, both alleles were deleted, and in the remaining 8 , one allele was deleted and the other rearranged. Furthermore, the rearrangement was confirmed with a second restriction enzyme in all but one sample. Finally, two-thirds of the rearranged $T_{\text {beta }}$ BamHI fragments were $>14 \mathrm{~kb}$, with a range from 10 to $32 \mathrm{~kb}$ (data not shown).

The $T_{\text {gamma }}$ findings in $T$ cell lymphoma differ somewhat from the $T_{\text {beta }}$ results, in part because of the limited recombinatorial possibilities of the $T_{\text {gamma }}$ variable region gene segments (Table III). BamHI again proved the single most useful restriction enzyme, revealing one or more rearrangements in 15 of the 18 cases (Fig. 2, lanes 9-16). However, EcoRI allowed easier identification of the particular rearranged $T_{\text {gamma }}$ frag-

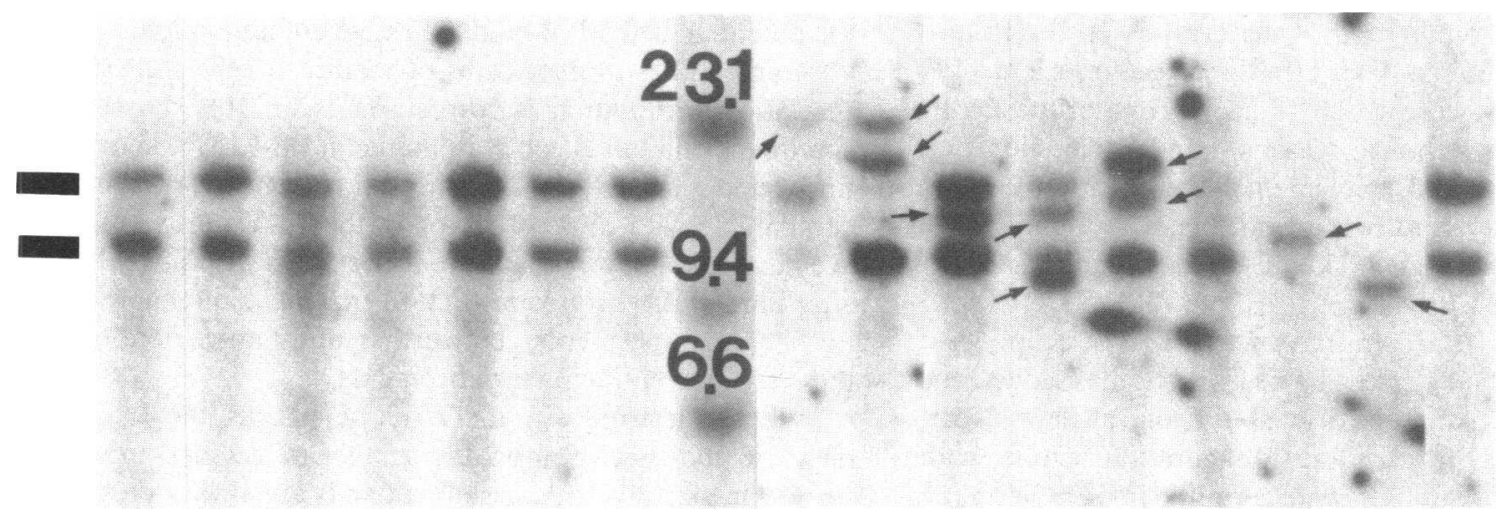

\section{7}

Figure 2. Rearranged $\mathrm{T}$ cell receptor gamma chain genes in $\mathrm{T}$ cell neoplasms (lanes 9-16). DNA was digested with BamHI and hybridized with a probe specific for the joining region of the gamma chain of the T cell receptor. Lanes 1-7 contain DNA from the B cell lymphomas 1-7, respectively in Tables I and II, and is in germline configuration. Lane 8 is a DNA molecular weight marker expressed in kilobase. Lane 9-16 contain DNA derived from T cell neoplasms.
Case numbers from Table III are listed in parenthesis: lane 9 (TALL, 5); lane 10 (CTCL, 1); lane 11 (ATL, 1); lane 12 (T-ALL, 1); lane 13 (CTCL, 2); lane 14 (ATL, 4); lane 15 (T-ALL, 2); and lane 16 (T-ALL, 3). Germline DNA from a patient with chronic myelogenous leukemia occupies lane 16 . The bars at the left of the figure indicate the germline position, and arrows point to the rearrangements. 
Table III. Configuration of the Genes for the Beta and Gamma Chains of the T Cell Receptor in $T$ Cell Malignancy and Non-T-, Non-B-ALL

\begin{tabular}{|c|c|c|c|c|c|c|c|c|}
\hline & \multicolumn{4}{|c|}{ Beta chain genes } & \multicolumn{4}{|c|}{ Gamma chain genes* } \\
\hline & Bam & Eco (C1) & Hind (C2) & Interpretation & Bam & Eco & Hind & Interpretation \\
\hline \multicolumn{9}{|l|}{ T-ALL } \\
\hline 1. Mac & $\mathbf{R R}$ & RD & RG & $\mathbf{R R}$ & $\mathbf{R} \mathbf{R}$ & $\mathbf{R R}$ & RRP & RR (I, VI) \\
\hline 2. Dud & $\mathbf{R} \mathbf{R}$ & $\mathrm{DD}$ & RRD & $\mathbf{R R}$ & RDD & RRR & RRDP & RRR (III, VI, VII) \\
\hline 3. Dub & RRR & DD & $\mathbf{G}$ & RRR & RDD & $\mathbf{R}$ & $\mathbf{R}$ & RD (VI) \\
\hline 4. Con & $\mathbf{R R}$ & $\mathrm{RD}$ & RRD & $\mathbf{R R}$ & RD1 & $\mathbf{R}$ & $\mathbf{R}$ & $R D(V)$ \\
\hline 5. Bro & $\mathbf{R R}$ & RD & RG & $\mathbf{R R}$ & $\mathbf{R}$ & $\mathbf{R}$ & $\mathbf{R R}$ & RR (I) \\
\hline \multicolumn{9}{|l|}{ CTCL (T4) } \\
\hline 1. Fag & $\mathbf{R R}$ & DD & $\mathbf{R}$ & $\mathbf{R} \mathbf{R}$ & RRD1 & D1 & G & RR (??) \\
\hline 2. Bor & $\mathbf{R R}$ & $\mathrm{DD}$ & RRD & $\mathbf{R R}$ & RRD1 & $\mathbf{R}$ & $\mathbf{R}$ & RR (VII, ?) \\
\hline 3. Cre & $\mathbf{R R}$ & RD & $\mathbf{R}$ & $\mathbf{R} \mathbf{R}$ & RD1 & G & $\mathbf{P}$ & RD (?) \\
\hline \multicolumn{9}{|l|}{ ATL (T4) } \\
\hline 1. $\mathrm{Chr}$ & $\mathbf{R} \mathbf{R}$ & $\mathrm{DD}$ & $\mathbf{R} \mathbf{R}$ & $\mathbf{R} \mathbf{R}$ & $\mathbf{R}$ & G & G & RG (?) \\
\hline 2. J-B & $\mathbf{R} \mathbf{R}$ & RD & $\mathbf{R} \mathbf{R}$ & $\mathbf{R} \mathbf{R}$ & RD1 & RDD & RDP & RD (VI) \\
\hline 3. $\mathrm{J}-\mathrm{C}$ & $\mathbf{R}$ & RD & $\mathbf{R}$ & RD & RD1 & $\mathbf{R}$ & RD & RD (VII) \\
\hline 4. J-E & $\mathbf{R R}$ & DD & RD & $\mathbf{R} \mathbf{R}$ & D1 & G & $\mathbf{P}$ & DD \\
\hline 5. J-H & $\mathbf{R R}$ & DD & $\mathbf{R R}$ & $\mathbf{R R}$ & RD1 & $\mathbf{R}$ & $\mathbf{R P}$ & RD (IV) \\
\hline 6. Fuk & $\mathbf{R}$ & RD & $\mathbf{R R}$ & $\mathbf{R R}$ & RRD1 & $\mathbf{R} \mathbf{R}$ & RRRP & RRR (III, IV, VI) \\
\hline \multicolumn{9}{|l|}{ T-CLL } \\
\hline 1. Fin(T4) & RG & RD & G & RD & $\mathbf{G}$ & G & $\mathbf{P}$ & G \\
\hline 2. $\operatorname{Car}(\mathrm{T} 8)$ & $\mathbf{R} \mathbf{R}$ & RD & RRRD & RRR & DD & RDD & RDP & RD (VI) \\
\hline 3. $\operatorname{Dat}(\mathrm{T} 4)$ & RG & RD & RRG & $\mathbf{R R}$ & $\mathbf{R R}$ & RRD1 & RD & RR (II, VI) \\
\hline 4. $\operatorname{Mas}(\mathrm{T} 4)$ & RD & DD & RD & RD & RDD & RRDD & RRDP & RR (I, IV) \\
\hline \multicolumn{9}{|c|}{ Non-T-, non-B-ALL } \\
\hline 1. Whi & RG & RG & G & RG & $\mathbf{R}$ & & $\mathbf{R}$ & RG (IV) \\
\hline
\end{tabular}

$D$, deletion; D1, deletion of the first constant region gene; $G$, germline; $P$, polymorphism; $R$, rearrangement. * The roman numerals designate the $T_{\text {gamma }}$ EcoRI fragments observed (see text).

ments that were of 7 different sizes and designated as follows in Table III (size in parentheses): I (5.4 kb), II (4.5 kb), III (3.1 $\mathrm{kb})$, IV (2.7 kb), V (2.5 kb), VI (1.7 kb), and VII (0.7 kb). Rearrangements III and V are observed much less frequently than the remainder. The seven fragments are similar, but not identical, to those reported by Quertermous et al. $(11,14)$ whose probe we employ. After HindIII digestion, we identify rearrangements that correspond to all but one of the EcoRI fragments, and, for technical reasons, HindIII digestion provides more sensitive and convenient identification of $T_{\text {gamma }}$ rearrangement. The HindIII fragments were of the following sizes (the corresponding EcoRI equivalent fragment is in parentheses): $5.3 \mathrm{~kb}$ (IV), $4.4 \mathrm{~kb}$ (V), $4.1 \mathrm{~kb}$ (VI), $3.8 \mathrm{~kb}$ (III), 3.1 $\mathrm{kb}$ (II), and $2.9 \mathrm{~kb}$ (I). In summary, both alleles of $\mathrm{T}_{\text {gamma }}$ were rearranged in 8 of the 18 cases of $T$ cell lymphoma studied, one allele was rearranged and one deleted in 7 , one allele was rearranged and one was in germline configuration in one, both were deleted in one, and both were germline in one. Germline alleles of the first constant region gene of $T_{\text {gamma }}$ could not be identified in 13 of the 18 specimens. (The polymorphism represented by the $5.0-\mathrm{kb}$ HindIII band was observed in 9 of the 18.)

\section{Discussion}

Clonal rearrangement of the gene for the beta chain of the $T$ cell receptor is a regular finding in neoplasms of $\mathrm{T}$ cell lineage (1-3). The question addressed in the present study is the speci- ficity of that finding to $T$ cell lineage. The repeated observation of rearrangement of both $T_{\text {beta }}$ and $T_{\text {gamma }}$ in non-T-, non-BALL (3-5, 14-16) indicates one instance of nonspecificity, but in certain respects that disorder is unique and may represent a special exception; i.e., ALL involves a stem cell that may retain the potential for both B- and T-lineage differentiation.

Our findings in neoplasms of mature B cells suggest that the latter formulation is correct. Thus, in 100 consecutive specimens of adult B cell lymphoma and B-CLL we have not uncovered a single example of $T$ cell receptor rearrangement comparable with those observed in the $18 \mathrm{~T}$ cell neoplasms. We have, to be sure, noted seven specimens with novel bands after BamHI digestion (a restriction enzyme that reliably picks up $T_{\text {beta }}$ rearrangements), but further study raises doubts that these are conventional rearrangements.

When compared with the $T$ cell neoplasms, the $T_{\text {beta }}$ fragments in the B cell tumors are smaller in size and more restricted in size diversity, germline bands are always preserved and are usually of equal intensity to the novel bands, and a rearranged fragment usually (five of seven instances) cannot be detected with restriction enzymes other than BamHI. Finally, the gene for the gamma chain of the $T$ cell receptor is always in germline configuration with multiple restriction enzymes.

These several findings in B cell tumors contrast sharply with the observations in $T$ cell lymphomas summarized in Table III. Every one of the $18 \mathrm{~T}$ cell neoplasms described therein has rearranged or deleted both alleles of the beta chain 


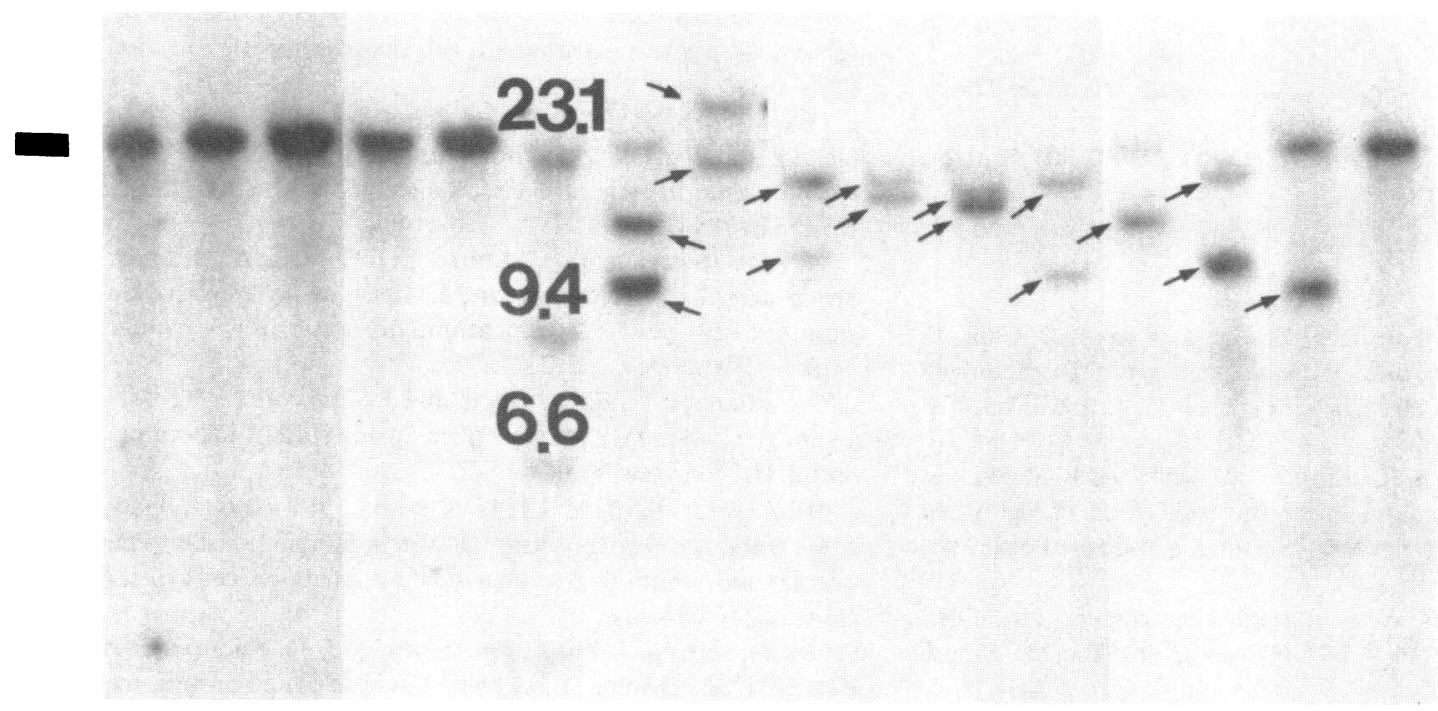

\section{6}

Figure 3. Rearranged T cell receptor beta chain genes in $\mathrm{T}$ cell neoplasms (lanes 7-15). DNA was digested with BamHI and hybridized with a probe specific for the beta chain constant region gene. DNA, in germline configuration, obtained from representative B cell lymphomas occupies lanes 1-5. Lane 6 contains a molecular weight marker expressed in kilobase. Lanes 7-15 contain DNA derived from $T$ cell neoplasms. Case numbers from Table III are indicated in

gene: in 15 , both were rearranged, and in 3 , one was rearranged and the other deleted. Further, the 11-kb EcoRI germline fragment containing the first constant region gene segment was never detected; both alleles had undergone either rearrangement or deletion. Finally, both alleles of the $T_{\text {gamma }}$ gene were in germline configuration in only one of the $18 \mathrm{~T}$ cell malignancies studied. Other investigators have also noted the regularity of $\mathrm{T}_{\text {gamma }}$ gene rearrangement in $\mathrm{T}$ cell neoplasia (13-15).

Thus, the pattern of $\mathrm{T}$ cell receptor genes in the $\mathrm{B}$ cell lymphomas is not the ordered picture observed in $T$ cell tumors. Rather, in the five cases in which rearrangement was observed with only one restriction enzyme (cases 1, 2, 3, 5, and 7 in Table II), the evidence favors an uncommon polymorphism of the $T_{\text {beta }}$ gene. In the two cases in which a nongermline $T_{\text {beta }}$ fragment was observed with two restriction enzymes but in which $T_{\text {gamma }}$ was in germline configuration (cases 4 and 6 in Table II), it is uncertain whether a single allele of $T_{\text {beta }}$ has undergone an early (possible diversity-joining segment) rearrangement (17) or if this represents multiple polymorphisms. Unfortunately, the samples had been in storage for several years, and it was not possible to recall any of these patients to obtain additional material with which to establish the germline configuration in nonlymphoid tissue. These conclusions concerning the $T$ cell receptor in $B$ cell lymphoma differ from the conclusions of one group of investigators based on preliminary findings (18). Those workers report rearrangement of the gene for the beta chain of the $T$ cell receptor in two of seven cases of B cell lymphoma, and rearrangement of the gamma chain gene in six. It is not clear from the published report whether the $T_{\text {beta }}$ rearrangements were confirmed with more than one restriction enzyme, raising the possibility that the reported parenthesis: lane 7 (ATL, 1); lane 8 (CTCL, 1); lane 9 (T-ALL, 5); lane 10 (ATL, 2); lane 11 (T-ALL, 2); lane 12 (CTCL, 2); lane 13 (ATL, 3); lane 14 (T-CLL, 2); and lane 15 (ATL, 6). Germline DNA from a patient with chronic myelogenous leukemia occupies lane 16. The bar at the left of the figure indicates the germline position, and arrows point to the rearrangements.

bands were similar to those analyzed in the present study. Some of the reported $T_{\text {gamma }}$ bands may represent the oligoclonal bands of nonneoplastic $\mathrm{T}$ cells, since $\mathrm{T}$ cells predominate in some monoclonal B cell tumors. The findings of another preliminary study (19) is in agreement with the present report.

We conclude from the foregoing that ordered rearrangement of the $T$ cell receptor gene is rare in adult B cell lymphoma and B-CLL. In this respect, the findings differ from non-B-, non-T-ALL, a pre-B cell neoplasm. In that disorder, which like the adult $B$ cell lymphomas under consideration exhibits rearranged Ig heavy chain genes (though usually not Ig kappa and Ig lambda) (6), 50\% of cases rearrange one allele of $T_{\text {gamma }}$ and about one-half of those also rearrange one $T_{\text {beta }}$ allele $(3,4,14,16)$. The single case of non-T- , non-B-ALL reported by us (5) also exhibited one rearranged allele of $T_{\text {beta }}$, and we record in Table III that one allele of $T_{\text {gamma }}$ is also rearranged. Clearly, different genetic mechanisms are at work in B cell lymphoma and non-T-, non-B-ALL.

From the available evidence, $T$ cell receptor gene configuration of $B$ and $T$ cell neoplasms appears to be less inconsistent than was first feared when the findings in non-T-, non-BALL became available. T cell neoplasms always rearrange both alleles of $T_{\text {beta }}$ and almost always both alleles of $T_{\text {gamma }}$, whereas B cell neoplasms rearrange at least one (usually both) Ig heavy chain allele(s) and at least one Ig light chain allele. Common ALL antigen-positive non-T, non-B ALL is exceptional in having rearranged one Ig heavy chain allele (but rarely a light chain allele), and frequently $T_{\text {gamma }}$ (about onehalf of the time) and $T_{\text {beta }}$ (one-quarter of the time) as well. Perhaps, the lineage of non-T- , non-B-ALL is more appropriately defined as pre-B, pre- $T$ rather than as pre-B alone. 


\section{Acknowledgments}

We are grateful to Dr. Thomas Quertermous for the gift of the $T_{\text {gamma }}$ probe and to Dr. Tak Mak for the gift of $T_{\text {beta }}$.

This work was supported by a research grant CA 30020-05 from the National Institutes of Health.

\section{References}

1. Minden, M. D., B. Toyanaga, K. Ha, Y. Yanagi, B. Chin, E. Gelfan, and T. Mak. 1985. Somatic rearrangement of T-cell antigen receptor gene in human T-cell malignancy. Proc. Natl. Acad. Sci. USA. 82:1224-1227.

2. Aisenberg, A. C., T. G. Krontiris, T. W. Mak, and B. M. Wilkes. 1985. Rearrangement of the gene for the beta chain of the T-cell receptor in T-cell chronic lymphocytic leukemia and allied disorders. N. Engl. J. Med. 313:529-533.

3. Minden, M. D., and T. W. Mak. 1986. The structure of the T cell antigen receptor genes in normal and malignant $\mathrm{T}$ cells. Blood. 68:327-336.

4. Tawa, A., N. Hozumi, M. Minden, T. W. Mak, and E. W. Gelfand. 1985. Rearrangement of the $T$ cell receptor beta chain gene in non-T, non-B acute lymphoblastic leukemia of childhood. $N$. Engl. $J$. Med. 313:1033-1037.

5. Aisenberg, A. C., and B. M. Wilkes. 1985. The genotype and phenotype of $T$ cell and non-T, non-B acute lymphocytic leukemia Blood. 66:1215-1218.

6. Korsmeyer, S. J., A. Arnold, A. Bakshin, J. V. Ravetch, U. Siebenlist, P. A. Hieter, S. O. Sharrow, T. W. Le Bien, J. H. Kersey, D. G. Poplack, P. Leder, and T. A. Waldmann. 1983. Immunoglobulin gene rearrangement and cell surface antigen expression in acute lymphocytic leukemias of $\mathrm{T}$ cell and B cell precursor origin. J. Clin. Invest. 71:301-313.

7. Aisenberg, A. C., B. M. Wilkes, J. Jacobson, and N. L. Harris. 1987. Immunoglobulin gene rearrangements in adult non-Hodgkin's lymphoma. Am. J. Med. 82:738-744.

8. The Non-Hodgkin's Lymphoma Classification Project. 1982. National Cancer Institute Study of Classification of Non-Hodgkin's Lymphomas. Summary and description of a Working Formulation for clinical usage. Cancer. 49:2112-2135.
9. Southern, E. M. 1975. Detection of specific sequences among DNA fragments separated by gel electrophoresis. J. Mol. Biol. 98:503-517.

10. Minden, M. D., B. Toyanaga, K. Ha, Y. Yanagi, B. Chin, E. Gelfan, and T. Mak. 1985. Somatic rearrangement of T-cell antigen receptor gene in human T-cell malignancies. Proc. Natl. Acad. Sci. USA. 82:1224-1227.

11. Quertermous, T., C. Murre, D. Dialynas, A. D. Duby, J. L. Strominger, T. A. Waldmann, and J. G. Seidman. 1986. Human T-cell gamma chain genes: organization, diversity and rearrangement. Science (Wash. DC). 231:252-255.

12. Maniatis, T., E. F. Fritsch, and J. Sambrook. 1982. Molecular Cloning: a Laboratory Manual. Cold Spring Harbor Laboratory. Cold Spring Harbor, New York. 545 pp.

13. Lefranc, M.-P., and T. H. Rabbitts. 1985 . Two tandemly organized human genes encoding the T-cell gamma constant-region sequences show multiple rearrangement in different T-cell types. Nature (Lond.). 316:464-466.

14. Greenberg, J. M., T. Quertermous, J. G. Seidman, and J. H. Kersey. 1986. Human $T$ cell gamma-chain gene rearrangements in acute lymphoid and nonlymphoid leukemia: comparison with the Tcell receptor beta-chain gene. J. Immunol. 137:2043-2049.

15. Goorha, R., N. Bunin, J. Mirro, S. B. Murphy, A. H. Cross, F. G. Behm, T. Quertermous, J. Seidman, and G. R. Kitchingman. 1986. Provocative patterns of the genes for the gamma- and betachains of the T-cell receptor in childhood acute lymphoblastic leukmia. Blood. 68(Suppl. 1):256.

16. Pelicci, P.-G., D. M. Knowles, and R. D. Favera. 1985. Lymphoid tumors displaying rearrangements of both immunoglobulin and T cell receptor genes. J. Exp. Med. 162:1015-1024.

17. Yancopoulos, G. D., and F. W. Alt. 1986. Regulation of the assembly and expression of variable-region genes. Annu. Rev. Immunol. 4:339-368.

18. Griesser, H., A. Feller, K. Lennert, M. Tweedale, H. A. Messner, J. Zalcberg, M. D. Minden, and T. W. Mak. 1986. The structure of the $\mathrm{T}$ cell gamma chain gene in lymphoproliferative disorders and lymphoma cell lines. Blood. 65:592-594.

19. Suber, M., P. G. Pelicci, A. Neri, D. Littman, D. M. Knowles, and R. Dalla-Favera. 1986. Different T-gamma rearrangement patterns in different cell types. Blood. 68(Suppl. 1):267. 